\title{
Training in Spanish organizations: Trends and future perspectives
}

Mạ J osé Rubio Hurtado ${ }^{1}$, Mạ Dolors Millan Guasch ${ }^{1}$, Flor Cabrera Rodríguez ${ }^{1}$, Antoni Navio Gámez ${ }^{2}$, Pilar Pineda Herrero²

${ }^{1}$ University of Barcelona (Spain), ${ }^{2}$ University Autonoma of Barcelona (Spain) mjrubio@ub.edu, dmillan@ub.edu, f.cabrera@ub.edu, antoni.navio@uab.es, pilar.pineda@uab.es

Received September, 2010

Accepted April, 2011

\section{Abstract}

Purpose: This study aims to identify training trends in Spanish organizations.

Design/ methodology/ approach: A survey methodology is conducted and the questionnaire is the strategy to collect information. In order to construct the sample, a previous selection of enterprises was done out of the 50000 enterprises registered at DICODI (Data base of main Spanish societies 2004/2005). The sampling was done by quotas. The quotas or categories selected were: the enterprises' activity sector, gender and job position.

Findings: The research describes the actual state of training trends and the changes that seem to glimpse out of the considered dimensions: training planning, goals, recipients, modalities, resources, evaluation, training professionals and outsourcing.

Research limitations: The study was carried out through a not randomized sample, so the results cannot be generalized.

Practical implications: Organizations can make future proposals from the facts exposed in our research. 
Originality/ value: Is the first time in our context that a research of this type is performed, showing significant matches in the results with other studies of international reference.

Keywords: training, trainers, industrial training, professional training, further training, lifelong training, professional continuing education

Jel Codes: M530

\section{I ntroduction}

Trend studies are not outside education and training. National and international organizations, as well as those worried about training, lead and promote them with the purpose to delimit strategic politics and, in short, to improve their actions. In the case of training, the American Society for Training and Development (ASTD) carries out an annual review on the training state of American companies, which has the characteristic to be a trend study in accordance to a series of variables or considered aspects (ASTD, 2005, 2004, 2003). In Europe, the CEDEFOP has conducted different sector studies related to the training in those organizations that incorporate aspects connected with trends into their development (Delcourt \& Planas, 1998; Sellin, 1998, 1999; Fries, 2003; Strietska Ilina \& Tessaring, 2005). However, a lack of global studies about training trends is stated.

The goal of trend studies is to respond to latent or potential needs, as they allow knowing the actual state of a given phenomenon, and thereby, making proposals for the future. In this sense, we can consider that scenario studies (Witkin \& Altschuld, 1995) or even the Delphi method (CEPYME, 2003; ALIAD, 2006; Cerezo \& Iniesta, 2006), applied to specific sectors, are methodological approaches that can be incorporated to trend studies.

Beyond their particular specifications, all trend studies share the fact of attending different dimensions, which undergo an analysis in order to show the evolution of the considered aspects. Therefore, on a company's training context, the first step to take is to delimitate the relevant analysis dimensions. In accordance with different proposals (Cabrera, Millan \& Romans, 2001; Pineda, 2003; ASTD, 2006), the main training dimensions in organizations are:

- Training planning 
- Training purposes

- Training recipients (trainees)

- Training modalities

- Training resources

- Training evaluation (assessment)

- Training professionals (trainers)

- Training outsourcing

Undoubtedly, the training planning is the starting point on training actions within the organizations. Nowadays, it is closely linked with the strategic plan of the enterprise, as a requirement for the training to be effective and to become a tactic to achieve the organization's objectives (EPISE, 2000; Pineda, 2003). Another fundamental aspect is the decentralization of the training planning, emphasizing the gradual implication of other areas and services of the organization into the plan, delegating functions and involving the managers into their collaborators' training and development (Reitman, 2006). Many studies show the convenience of the workers' involvement in the training planning and specially, in the identification of needs, in order to increase the training efficiency and to strengthen the motivation and the implication of the human resources into the enterprise project (Font \& Imbernón, 2002). Studies also emphasize the convenience to establish individual training itineraries in order to come up better to the specific needs of each person and to be able to link the training with career plans, promotions or other human resources' development strategies (ASTD, 2006). These training planning variables are prioritized in this trend study.

Organizations' training must be oriented to the achievement of the objectives and purposes of the enterprise (Grünewald, 1996; Rubio, 1996; FORCEM, 2000). In the European context, Tessaring's open and integral proposal (1999) is particularly significant. The author proposes six functions, that are, from our point of view, intrinsic purposes of training actions in the organizations: adaptation, innovation, promotion, compensation and prevention. Undoubtedly, the development of these purposes is strongly connected to the organizations' typology, its recipients and the needs that must be fulfilled. 
The recipients of training -trainees- are the participant groups to whom the training actions are directed. We have used the four basic categories, which coincide with the ones proposed by FORCEM, la Cambra de Comerç de Barcelona (2003) and Millan (1995): regular staff, technical staff, middle managers and director managers.

Training modalities respond to the way the training is organized and carried out (Millan et al., 2005). Two groups of variables have been considered: on one hand, traditional classroom training (conventional face-to-face mode) and virtuality (online) and on the other, the training individualization. The first group of variables respond to the fact that, nowadays, training can be delivered in three different ways: traditional (conventional), virtual (online) and blended (ASTD, 2004; Fundación Tripartita, 2004). The second group is justified because of the presence of modalities that intend to fulfill the concrete needs of professionals and their job position, which thereby, create individual training itineraries.

Resources are the available means that an organization has to conduct the training actions, such as personnel, infrastructure and financing. Economical streamlining prevails within the range of enterprise management (Delcourt \& Planas, 1998) and this includes training. It is therefore usual to take into account the staff recruitment (internal or external), the premises, the equipment, the training materials and the financing mechanisms (internal or subsidized).

The training assessment is the procedure that allows an organization to make a survey on the training and to take decisions. The important items to be considered within the evaluation (Cabrera, 2003; Pineda, 2002; Rubio, 2003) are the type of evaluation done (learning, job position transference or impact in the organization), the tools employed, evaluation usefulness and the application of quality management processes.

Undeniably, the training development in organizations requires professionals who assume different degrees of responsibility. Beyond the trainer figure, which has been described in several ways by different studies (e.g., Darling et al., 1999; EPISE, 2000; Selka, 1999; Navío, 2005; Rubio, 1996), the future organizations must professionalize their workers in order to make them adopt responsible roles on the training area. It is therefore important to prepare them since they will be able to assume different professional profiles, and this will represent the key factor that will allow the organizations to become settings of knowledge management, of skills generation and of permanent learning. 
The organization's outsourcing is the practice by which some activities are recruited from external sources, usually those that are not strategic for the company. Some studies show that this is an existing phenomenon in organizations and that it will be increased in early dates (Sennett, 2006). The actual research is centred in detecting outsourcing trends for the personnel training.

It is within the context described above, that the Training in Organizations Group from the Barcelona University (E-FORG) considered the need to detect the continuing training trends within the Spanish enterprises' reality. A research concluded in 2005 had for purpose to determine the indicators that will enable the study of training trends in Catalonia (Millan et al., 2005). A qualitative methodology was conducted, based on in-depth interviews directed to the training experts of different segments of the Catalonian economical activity. As a result, a series of indicators were obtained for each of the principal training dimensions, which were subsequently used to design the present research. As a complement for the previous research, the present one considered as fundamental the opinion of the organizations' management directors and training managers, and this study was extended to all the Spanish territory.

Thus, the principal objective of the present study is to identify the Spanish continuing training trends for the years to come. This general objective includes the next specific purposes:

- To detect trends in the training plan elaboration

- To detect the training purposes that will tend to be most important in a future

- To detect the type of recipients who tend to receive training

- To detect trends on the training modalities that will prevail in the future

- To detect trends on the employment of resources used for training

- To detect the training professionals' knowledge and their role that will tend to prevail on the future

- To detect the training aspects that will tend to be outsourced. 


\section{Methodology}

The method has followed the survey studies characteristics, oriented towards a diagnosis of a real situation.

\section{Tool selected for information collection: Questionnaire}

The tool selected was the questionnaire, a technique that allows to measure what a person knows (knowledge or information), what she does (behaviours), what she pleases or dislikes (values and preferences) and what she thinks (attitudes and beliefs).

\section{Dimensions and variables of the questionnaire}

The questionnaire proposes a series of organized questions according to dimensions and variables fixed in advance, following the research objectives.

The questionnaire includes two parts: the first one contains the identification data or sociodemographic aspects of the informants, related to the personal, training and professional experience variables. In short: age, sex, organization's activity sector, degree of job's responsibility, years of experience in training, and their initial and continuing training (Table 1 ).

The second part of the questionnaire is integrated by organized questions around 8 dimensions which are the objectives of this research. Table 1 shows the questionnaire structure with its dimensions and the variables considered for each one of them.

\section{Expert validation}

\begin{tabular}{|c|c|}
\hline Dimensions & Variables \\
\hline Training planning trends & $\begin{array}{c}\text {-Centralization/decentralization } \\
\text { - Needs detection } \\
\text {-Connection with the enterprise strategy } \\
\text {-Training itineraries }\end{array}$ \\
\hline Purposes of training trends & $\begin{array}{c}\text {-Purposes oriented to enterprise strategy } \\
\text {-Purposes oriented to staff development } \\
\text {-Purposes oriented to staff training } \\
\text {-Purposes oriented to innovation and change }\end{array}$ \\
\hline Trainees trends & $\begin{array}{c}\text {-Internal staff of the company (director managers, middle } \\
\text { managers, technical staff and regular staff). }\end{array}$ \\
\hline Training modalities trends & $\begin{array}{c}\text {-Traditional classroom training / virtuality (online) } \\
\text {-Training personalization }\end{array}$ \\
\hline Training resources trends & $\begin{array}{l}\text {-Personnel } \\
\text { - Infrastructure } \\
\text {-Financing }\end{array}$ \\
\hline Training evaluation trends & $\begin{array}{l}\text {-Evaluation levels } \\
\text {-Evaluation techniques } \\
\text {-Evaluation systems }\end{array}$ \\
\hline
\end{tabular}




\begin{tabular}{|c|c|}
\hline Professional trainers trends & $\begin{array}{c}\text {-I mportance of training responsible } \\
\text { Training outsourcing trends }\end{array}$ \\
$\begin{array}{c}\text { - Different aspects of planning (needs detection, planning } \\
\text { design, training actions design, training delivery, public help } \\
\text { management, training evaluation, resources evaluation). }\end{array}$ \\
\hline
\end{tabular}

Table 1. Questionnaire structure

The questionnaire was validated by seven experts (six on continuing education and one technician on measuring procedures), who have valued the content of the questionnaire regarding the comprehension, pertinence and importance of each of the questions in relation to the objectives that they represent. The validation results allowed to improve the formulation of some questions, to better arrange in sequence the ones that constitute a battery between them, and to eliminate the non relevant aspects for the study objectives. After the present validation, a final protocol was designed, which figures on the appendix.

\section{Sample}

The population studied at the present research is composed by training professionals who work in organizations. To construct the sample, a previous selection of enterprises was done, out of the 50000 enterprises registered at DICODI (data base on the principal Spanish societies, 2004-2005) since the research context includes all the Spanish territory.

The sampling type has been done by "quotas". It is based on the proper knowledge of the population stratus and/or the most representative or appropriate individuals for the goals of the research. The quotas or categories selected were the enterprises' activity sector, gender and job position. Therefore, the informants should fulfill the following requirements: to belong to different sectors of enterprises' activity (ten or more), both genders being represented and to hold one of the next job positions: Human Resources Responsible, Training Responsible or General Director.

The questionnaire was sent via electronic mail (e-mail) to the 1500 cases that fulfilled those requirements. Eighty five responses were obtained. Once analyzed, the stability of the sample was confirmed, by sending a third reminder e-mail to 15 persons else. When the low variability of the responses was proved, the sample was considered saturated and was given by definitive with a total number of 100 respondents, since the study did not pretend to realize a differential sector analysis. 


\section{Sample characterization}

The 100 persons that answered the questionnaire have a medium age of 39 years (with a typical deviation of 9,8 years), and they are women in $61 \%$ of the cases. Their job positions are distributed among technician or manager training (31\%), and training or human resources responsible ( $26 \%$ and $21 \%$ respectively). The rest $(21 \%)$ occupies positions like general directors, consulters, trainers or non specified. The enterprises belong to the tertiary sector $(51 \%)$ or secondary sector $(45 \%)$ and within the latest, primarily to the manufacturing industry. With this variability on surveyed people, the quotas of the sampling were confirmed.

A majority $(68 \%)$ holds a 5 to 8 years experience or more than 8 years on the training sector, which allows validating the consistency of the answers related to the respondent's experience.

On behalf of the initial training, almost the totality of the sample holds a university degree or diploma (97\%), with an important presence of Organizational Psychology and Education. Laws and Economics also appear but in a lesser degree.

In relation to the continuing training, $29 \%$ stated to have done different activities related to a particular type of training, $29 \%$ have coursed a master or postgraduate studies related to training or human resources and $31 \%$ have done one of the above mentioned. Only $7 \%$ of the respondents possess no more than their initial training.

\section{Findings}

Results presented below respond to the percentage analysis done for each of the items of the eight dimensions considered at the research. The table that concentrates the percentages can be seen at the appendix. To know the statistic significance of the differences found between the percentages of the items categories, the Chi square test was used, eliminating the " $b$ " and " $d$ " categories (trend to decrease and non contemplated aspect at the organization), since they were not relevant due to the low percentage observed. Significant " $\mathrm{p}$ " are discussed at the results.

\section{Training planning trends}

The data obtained show a strong trend to increase the connection between the training planning with the strategic plan of the organization, as indicated by $78 \%$ of the sample (with a $p=0,00$ ). This is due to the increasing coincidence of the 
strategic role of training to achieve the organization's goals and to the human resources professionals' will to be so.

In relation to the training plan elaboration, almost half of respondents consider that there is an increasing trend towards decentralization (41\%). It is a reality on organization management and it will be consolidated in a near future (even though centralization is still present). It is necessary to bring closer the decision making to the affected areas and to share responsibilities in that respect. The better way to respond to this need is the decentralization, which also affects the training. A trend to decentralize the training plan elaboration is therefore detected, in order to give a chance to the affected personnel to get involved in the process, to assume responsibilities and to take decisions to make training more effective. Training decentralization usually takes form as:

- Identification of needs by departments

- Planning by areas and

- Delegation of functions to middle managers.

Another important trend revealed by this study is the identification of needs by workers themselves (increases for $57 \%$ of the sample). This trend confirms the previous one related to decentralization: a major involvement of workers for the detection of needs implies the increasing decentralization of the training planning.

This major involvement of workers makes also clear another phenomenon: the introduction of participation strategies within the organizations, that also affects training. Thus, this trend shows that the training planning is elaborated on a more participative way, creating spaces for the workers to express their training needs and to reach agreements with managers and training responsible.

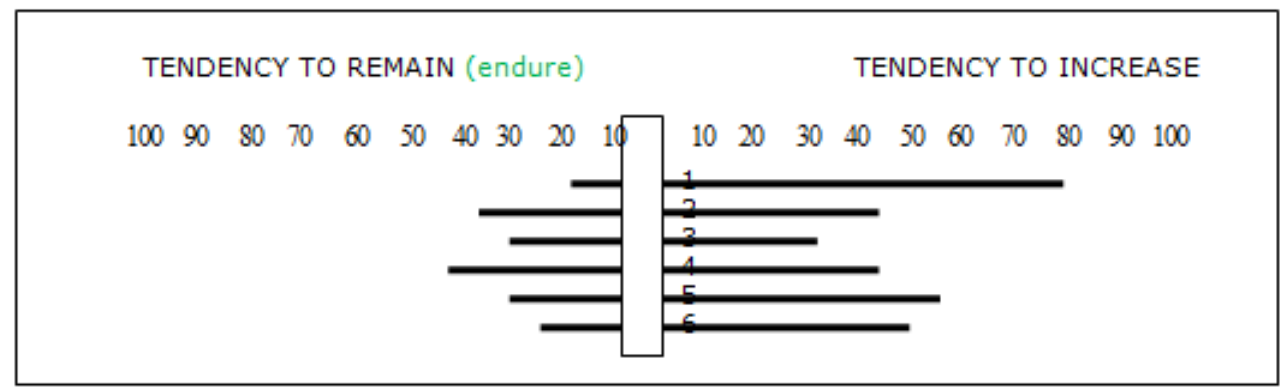

* 1.To link the training planning to the strategic plan of the enterprise; 2.To elaborate the training plan on a decentralized way; 3.To elaborate training plan on a centralized way; 4 .Director managers detect needs; 5 .Workers detect needs by themselves; 6 . Establishment of personal training itineraries. 
Figure 1. Training planning trends (percentages)

Results also show the trend to establish individualized training itineraries (increases for the $5 \%$ of the sample, with $p=0,004)$. This indicates that a general perception prevails on organizations that generalized and homogeneous training directed to big groups of workers is not appropriate in many cases. An individual training is perceived as more efficient, oriented to fulfill the specific training needs of one person and conducive to an efficient transference into his/her job position. Both trends described above, are manifested on the strategy adopted by many organizations: the worker settles his own training itinerary, so a qualitative and individual approach is adopted. Figure 1 shows those results.

\section{Trends on training purposes}

Respondents' opinions on the training purposes trends make evident that this aspect is important. Results show that the considered aspects (Figure 2) will increase in a future within the organizations (all differences being significant with $p$ lower to 0.01). It is also shown that these aspects are going to decrease very little, as stated by a $4 \%$ of respondents.

According to the replies, the contribution of training to achieve the organization's objectives will rise considerably $(80 \%)$. This may indicate that a training increasingly linked to the enterprise needs is considered important. On the same way, it is observed that training directed to the workers' professional development will considerably increase. This development, besides of being connected to the training strategic plan, has a lot to do with training actions that will be more varied on strategies and modalities, and will be linked to the organizations needs and of course, to the participants needs. Another trend to stand out is the role of training as a facilitator of change processes, foreseeing these changes in the organizations. It is also important the rising trend to overcome job problems and difficulties, which means that training in organizations, is connected to the enterprise needs, specifically to problems that occur inwards, as well as problems related to job development. This can conduct to an opposite interpretation, since training in organizations can still be strongly linked to the day-by-day actions. Nevertheless, the percentages related to change facilitation and innovation promotion suggest that these are aspects that complement the need to get through daily problems. Therefore, it can be said that there exists a clear tendency in surveyed organizations that training is a fundamental element. 
Even if there exists a significant trend towards a training directed to personal development ( $54 \%$ of respondents considered it so) with respect to their actual situation ( $32 \%$ ), this aspect is considerably lowest than other. It is important to say that, even if the topic of personal development of workers is having a deep effect on organizations and that it is now usual to mention it in specialized forums, the truth is that it does not worries with the same intensity as other considered purposes of training. Without a doubt, many interpretations can be done on the subject, particularly taking into account the actual state of the work market.

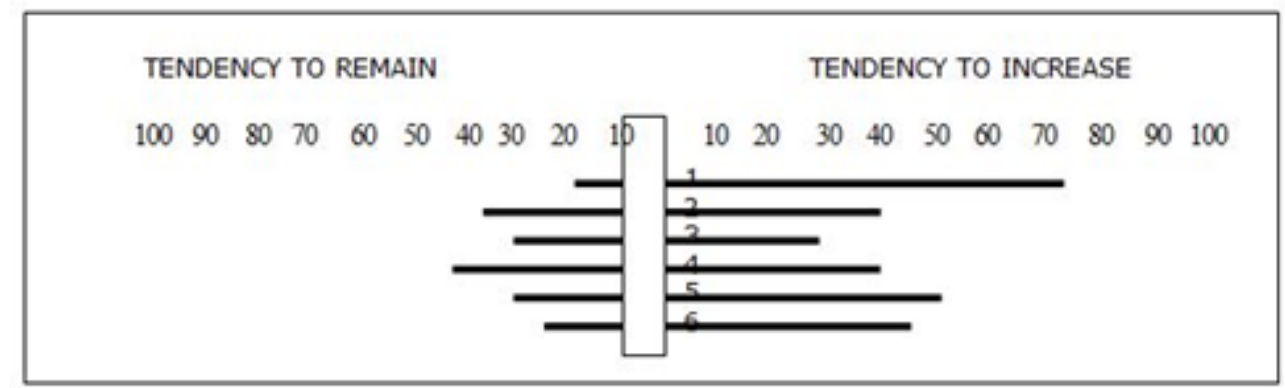

* 1. Achievement of strategic goals of the enterprise; 2 . Professional development of workers; 3. Personal development of workers; 4 . Staff motivation and satisfaction; 5 . Go through job problems and difficulties; 6 . Facilitation of change processes; 7. Improve innovation, integrate and share the organization's culture.

Figure 2. Training purposes trends (percentages)

Finally, another issue that tends to stand out amongst training purposes, is its contribution to create and share the organization's culture, as stated by $62 \%$ of the respondents, against a $31 \%$ that considers that it will remain the same. As demonstrated on the table of results (see appendix), not one considered aspect shows a tendency to decrease.

\section{Trends on training recipients}

Results on training recipients trends show a light but increasing tendency of the training directed to all the personnel, and a strong tendency to rise for the group of middle managers (with a $66 \%$ and being the only group with significant differences on behalf of the other options, $p=0.01$ ). These results are coherent with the training decentralization trend, since both reflect the actual situation in organizations where the structures tend to level and middle managers tend to get more involved on team management functions. 


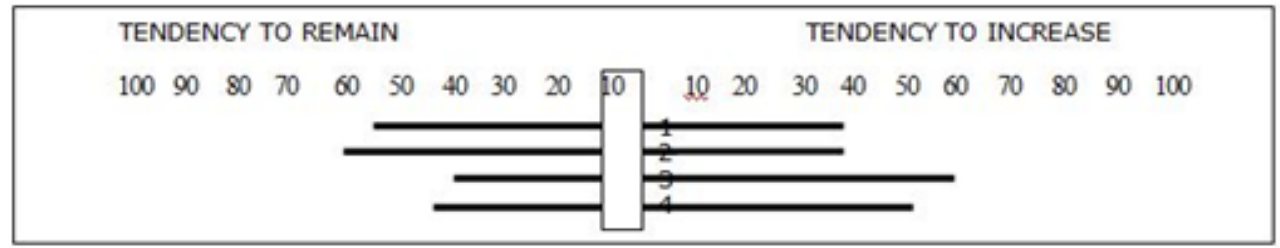

* 1.Regular staff; 2.Technical staff; 3.Middle managers; 4.Director managers

Figure 3. Training recipients trends (percentages)

Results can be seen at figure 3, where the trend to decrease is not represented since not one considered aspect shows that (see table of results in appendix).

\section{Trends on training modalities}

Results obtained for this trend, show significant differences in all cases, with $p$ lower than 0.01 .

In respect to traditional classroom - conventional face-to-face training (courses, workshops, seminars, masters and postgraduate studies), 30\% of respondents consider that the trend is in rise, $11 \%$ that it decreases and $56 \%$ that it remains the same. It can be considered that within the enterprises, there is a tendency to suppose that traditional learning situations generate the development of professional skills and collective intelligence and that individual skill need collective skills to get developed; also, that training is still a collective process, an activity that takes place in groups and its efficiency depends on the group.

Virtual training modality is increasing; a $53 \%$ consider that it is in rise and $27 \%$ thinks it remains the same. This can be interpreted in many ways, for example: the facility to have access to technical information needed for the work, the costs reductions, and the convincement that workers have an independent learning capacity and can diagnose their own training needs.

The clear trend of blended learning (combination of conventional-virtual training) to increase, as shown by a $72 \%$ of respondents, can be explained by the interest of enterprises for the social competences development and by the facility to have access to technical information by means of virtual resources. Only $1 \%$ states that it is decreasing and $12 \%$ that it remains the same.

Coaching, mentoring and internal consultancy trend is increasing, as shown by a $45 \%$ of respondents, while $1 \%$ thinks it is diminishing and $23 \%$ that it stays the same. The question to ask is whether they are thinking on a "tailor-made" training 
or on a "serial" one. On one hand, individualization of training satisfies the worker since it allows him/her an individual training itinerary, and on the other hand, it satisfies the company since this modality fulfils its needs with greater accuracy. However, individualization can lead to monopolize information and to restrict the collective intelligence development. It is important to mention that $29 \%$ of respondents think that this topic is not contemplated within their enterprises, which indicates that those training modalities are not yet implemented in all the organizations.

Learning at job position tends to increase, as said by $56 \%$ of enterprises, and $33 \%$ think that it will endure. Enterprises train and qualify their personnel by the daily resolution of the various problems encountered at work, with the working team or with the project.

To privilege the practical knowledge transmission that can only be valid for the enterprise and cannot be used in another job position may resolve the punctual problem of the organization but that does not favor the hiring possibilities of the workers.

Results can be seen at graphic 4, where the decreasing trend is not presented since not one considered aspect shows a clear tendency to decrease, as shown in the table of results (see appendix).

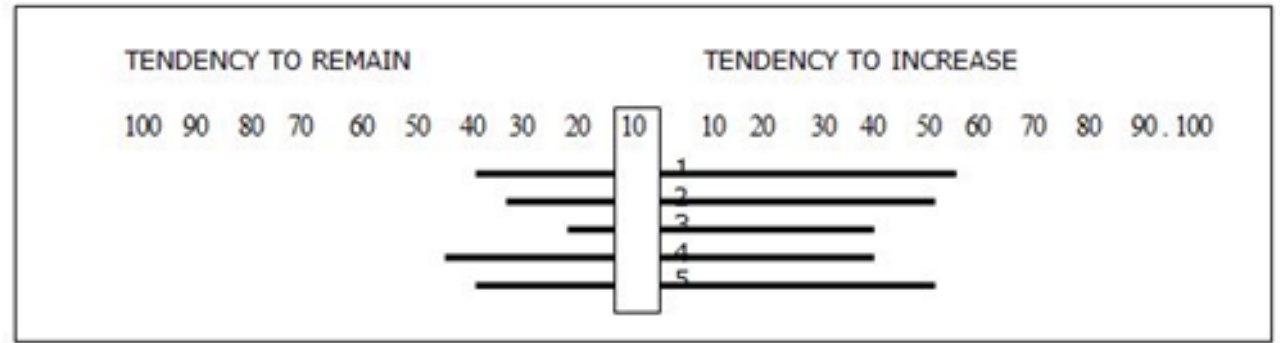

* 1.Traditional training; 2.Virtual training; 3. Blended learning; 4. Coaching, mentoring; 5.Training on job position

Figure 4. Training modalities trends (percentages)

\section{Training resources trends}

Results for this dimension show a light tendency to increase in some cases and to persist in others. The most clear tendency to augment (with a $69 \%$ and with a high level of significance for the differences found, with $p=0.00$ ) is the one that uses digital format materials for training (i.e., webs, multimedia CDs, power points, pdf documents). The paper saving, the fast actualization of contents allowed by some 
formats and the possible pedagogical advantages that can be provided by some digital materials, are key arguments to interpret this trend. Nevertheless, the high production costs of good multimedia materials might conduct the choice for more economical formats (pdf, doc and html). As a complement, paper materials tend to persist $(57 \%)$ or decrease $(19 \%)$. The classical format will not disappear, information will be duplicated in 2 formats or will be recorded digitally.

The tendency to use technological materials is also confirmed: the use of simulators increases with a 33\% trend, even if an important percentage of enterprises (39\%) do not contemplate this issue (what can be explained because in some activity sectors the use of simulators is not pertinent).

Regarding financing, it is clear that there is a growing tendency to obtain it by means of external grants (with a 51\%) and to keep the awarded for training as an internal resource of the organization $(59 \%$ with $p=0.002)$, what can mean that enterprises do have the intention to invest more in training but appealing to external helps.

Regarding external human resources, there is not a clear tendency, since replies to the item "hiring external personnel" are almost the same, with a 35\% that states that it will increase and a $36 \%$ that it will remain. A better definition appears regarding internal personnel dedication to training, that will augment according to $55 \%$ of the sample $(p=0.046)$.

Results can be seen at graphic 5, where the tendency to decrease is not presented since not one considered aspect shows a clear and evident trend in that respect (see table of results at the appendix).

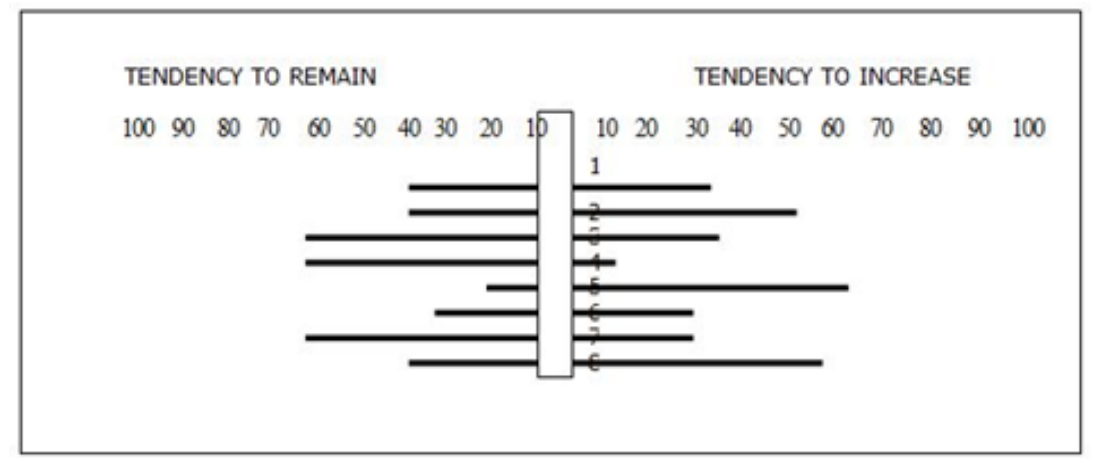

\footnotetext{
* 1.To hire external personnel; 2.To engage internal personnel; 3.To fit out local training spaces; 4.To use printed materials; 5 . To use digital formats materials; 6.To use simulators; 7.Financing with own resources; 8.Financing with external grants.
}

Figure 5. Training resources trends (percentages) 


\section{Training evaluation trends}

Results make clear that this dimension will tend to be more considered in a future than nowadays. Making some exceptions (that will be commented further), the training evaluation aspects that have been considered in this study, show substantial high values in their tendency to increase. In nine of the 10 aspects, a minimal of $47 \%$ of surveyed people (in some cases it reaches $66 \%$ ) thinks that it will augment, face to a maximum of $3 \%$ that considers that it will tend to decrease.

On the respondents' opinion, three are the aspects that stand out and should be taken in consideration for the future (all of them with $p$ lower than 0,01 in their tendency to increase). The first one is to elaborate the evaluation approaches by linking them to the training planning (as manifested by $66 \%$ of respondents, face to $21 \%$ that thinks that it will persist). The second is to endeavor the evaluation of the training effects further over the learning objectives, which means, to value the transference to the job position of knowledge and abilities acquired during the courses or other training means (also a $66 \%$ face to a $28 \%$ that thinks it will endure). The third, very linked to the previous one, is the growing tendency to evaluate the impact of the training within the organization $(62 \%$ face a $28 \%$ that considerate that it will persist).

Another result that stands out is the increase of percentages in relation to the use of qualitative evaluation strategies face to a possible reduction of quantitative ones. Thus, $50 \%$ of enterprises recognize an increasing use of observational or interview techniques in evaluative analysis (facing a $28 \%$ that considers that it will persist), while only a 38\% thinks that the application of narrower and quantitative procedures such as tests and questionnaires will increase (face to a $48 \%$ that think it will endure). Nevertheless, this trend did not work out to be significant at the Chi square contrast.

In respect to the type of evaluation commonly used in training, such as "satisfaction evaluation", it does not present a clear future trend. Thus, $47 \%$ of surveyed enterprises state that it will exist an increase in satisfaction evaluation, while a $50 \%$ considers it will endure because that kind of evaluation is already implemented.

To finish, it is important to point out that a relative percentage of enterprises $(12 \%)$ do not use any kind of quality system, even if they show a tendency to increase ( $47 \%$ state so). Amongst those that use a quality system, ISO standard is the most employed, followed by far by EFQM. 
Results are expressed in figure 6, where those aspects related to training evaluation that clearly tend to be more used in the future can be appreciated when compared to the actual level. The backward movement of some aspects as quantitative techniques or as the aspects that might have an equal importance as today's can also be appreciated. We did not considered to include the contrast graphic between the increase and the decrease trends since, as shown in the table of results included in the appendix, not one evaluative aspect considered shows a tendency to decrease.

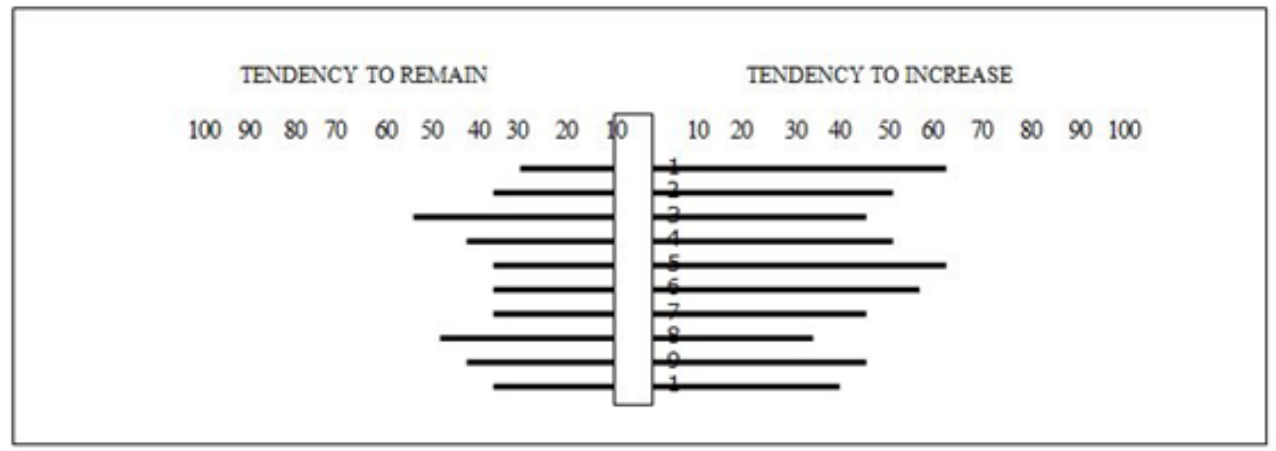

* 1. Link evaluation to planning; 2. Initial evaluation of skills; 3. Satisfaction evaluation; 4.Learning evaluation; 5.Transference to job position evaluation; 6.1 mpact on organization evaluation; 7.Training efficiency evaluation; 8.Use of quantitative techniques; 9.Use of qualitative techniques; 10. Use of quality management systems

Figure 6. Evaluation trends: comparison between tendency to remain and tendency to increase (percentages)

\section{Trainers' trends}

In this respect, it was observed that organizations tend to maintain or increase the number of human resources and professional level of people related to the training departments.

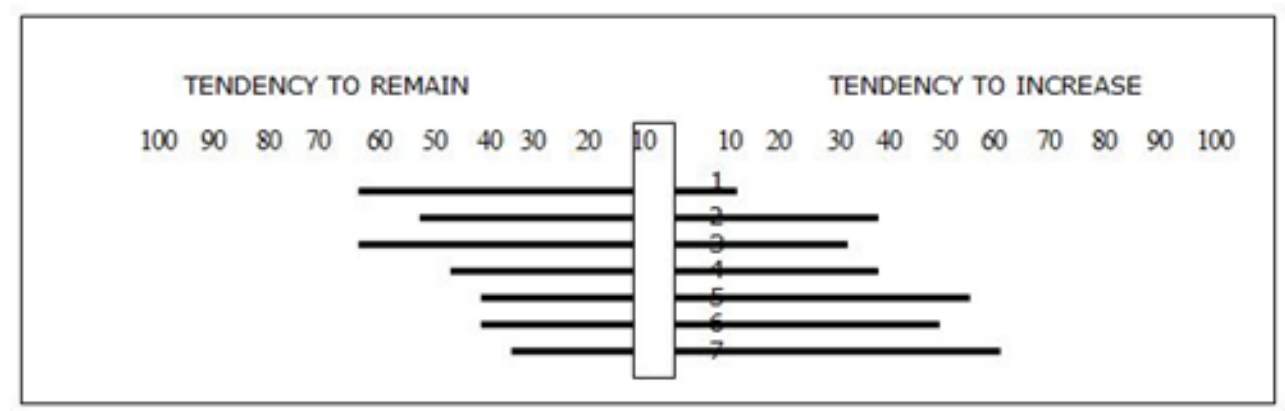

* 1.To incorporate personnel dedicated to training; 2.To professionalize personnel dedicated to training; 3.Presence of a responsible for training; 4.Need of knowledge on enterprise management; 5 . Need of 
knowing the activity sector of the organization; 6.Pedagogical knowledge; 7.To possess interpersonal abilities.

Figure 7. Professionals of training's dedication trend (percentages)

It is noteworthy that more than half of enterprises expect to increase the professional profile of their workers by training them on specific knowledge on their activity sector $(60 \%)$. The same can be said in respect to the enterprises' interest to provide them with pedagogical knowledge (55\%) for their work development and with abilities on human relations $(65 \%)$, as well as enterprise management knowledge $(40 \%$, being the only non significant option with $p=0.413)$.

Results can be seen on figure 7, in which the tendency to decrease is not represented since not one aspect considered shows it so.

\section{Training outsourcing trends}

Results for this dimension do not show significant differences between the opinions of people who consider that it will endure and those who think that they will increase in a future, for none of the considered aspects. A possible explanation is that organizations are already outsourcing and they do not expect a significant increase in this respect, or that they do not consider it necessary.

As for the obtained percentages, it is observed that approximately a $30 \%$ of surveyed organizations consider that outsourcing will augment, standing out the training delivery, the management of public grants and the training materials elaboration. This demonstrates the initial idea that organizations tend to outsource those elements that are not strategic for their activity.

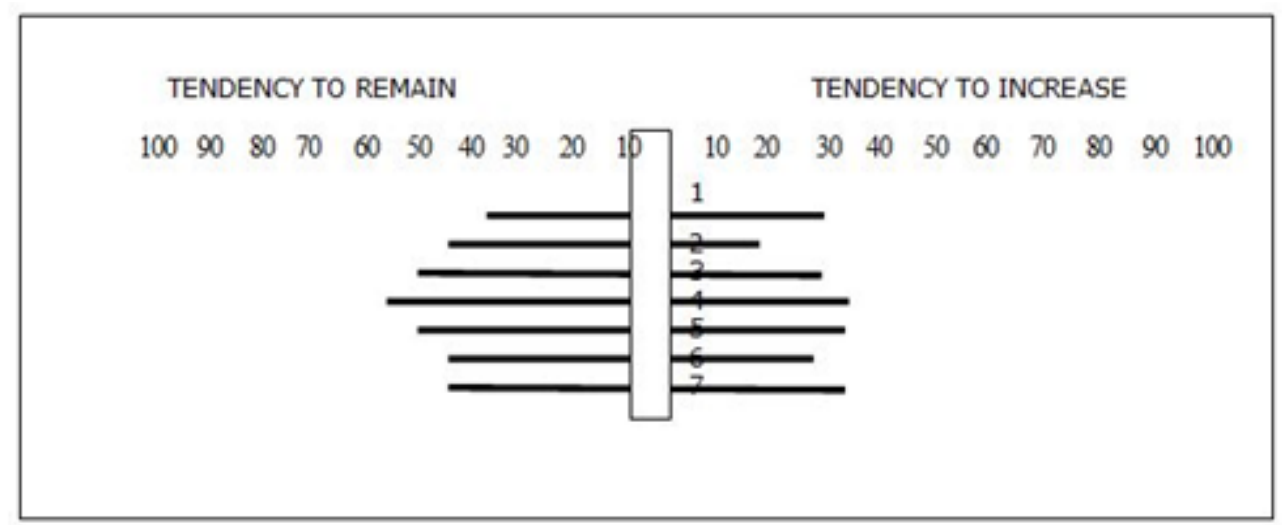

* 1. Needs detection; 2.Training planning design; 3.Training actions design; 4.Training delivery; 5.Public grants management; 6.Training evaluation; 7.Elaboration of training materials

Figure 8. Training outsourcing future trends (percentages) 
In fact, experts believe that a complementation between internal and external training measures should exist and that, with the new forms of work organization that arose from the internet technologies, it is difficult to establish limits between the companies' interior and exterior.

Results can be observed at figure 8, where tendency to decrease is not presented since not one considered aspect shows that trend, as seen in the table of results included at the appendix.

\section{Conclusions}

\section{Research limitations}

The study should be complemented with interviews to experts and consulting professionals in order to compare their answers with those of the professionals who participated in our research.

The sample should be higher and random, from the total of Spanish enterprises that impart training.

\section{Practical implications}

Enterprises can make future proposals from the facts exposed in our research. These facts are summarized below:

Training purposes trends clearly show that, in a future, training becomes a strategic element of the enterprise. Thus, training will contribute much more to the achievement of the enterprise's purposes, will increase its role to potentiate the professional development of workers and will be a key tool to facilitate change processes. More than ever, the organization will need to count on training as a crucial element to confront the challenges of the actual society. It is imperative that the organization commits with the continuing learning as a fundamental strategy to free the talent and experiences of people in order to induce changes and needed innovations, to be able to adapt in a creative way to its context demands and to the cultural internal dynamics generated by the change process.

Related to the training recipients, we can conclude that the trend to direct the training to middle managers will increase, and in a lesser degree, the one addressed to director managers. Once again, it is evident the need to favor the implication and commitment of people in organizations. 
In respect to the training modalities, virtual training will increase as well as training in job position. As a result, the use of virtual materials for training will augment. In parallel, an increase in public investment for training will be appreciated, as well as the internal professionals that manage the training. As it happens in other organization areas, training decisions will become more complex since more elements should be taken into account, elements that are multiplied, diverse and interconnected.

As for the training evaluation, even if there is an increasing trend, it does not seem that the future approaches will go further than the traditional practices. Thus, even if there is a prediction of an increase in the use of qualitative techniques, it does not represent a significant trend face to the use of quantitative techniques. For the training evaluation to become a useful tool, it is necessary that the new conceptions and evaluative strategies enter the organizations. That is how the evaluation process should overcome its training control function to change into a service process for improvements, change and training learning (Cabrera, 2003). In accordance with the actual management of organizations, it is necessary to transform the evaluation into a tool of democratic management, available for everyone direct or indirectly implicated in the training processes in order to make them aware of the success or mistakes of training, to learn about experience, be more self-responsible, more effective and more efficient. As stated by Mateo (2000), evaluation generates an evaluative culture, the construction of values that are incorporated into the people and organizations' culture, while favoring change processes. With a more participative approach and within the actual qualitative trends, training evaluation can play a significant role in the processes and results assessment, and in learning-the-lesson about the training activities undertaken in organizations.

Finally, the processes of training outsourcing will remain the same, except for the case of management for public grants for training which will be outsourced even more.

\section{Social implications}

The globalization phenomenon and the continuous changes in actual society generate deep environment transformations that locate the organizations in new action settings and expose them constantly to unpredictable and unexpected results. We are facing a more informed and demanding society, much more competitive, less centralized and stable, more willing to get oriented towards 
individual needs, more complex and more worried about the environmental damage.

Organizations are feeling the need to get restructured on a more flexible way, with more autonomy between the various hierarchy units and capable of giving accurate answers to unclear and troubled social contexts. As Senge $(1993,2006)$ defends enterprises will have a future if they are able to discover how to make good use of the enthusiasm and learning capacity of people that are part of them in all levels of organization.

Without a doubt, this scene creates new challenges to the organizations, and in a particular way, to their department or responsible area of the training direction and management.

As a conclusion, the results obtained in the present study allow us to identify, for the near future, some clear trends for training in the Spanish organizations. This results show:

- Trend to decentralize the training plan elaboration is therefore detected, in order to give a chance to the workers to get involved in the process, to assume responsibilities and to take decisions to make training more effective.

- Introduction of participation strategies within the organizations, creating spaces for the workers to express their training needs and to reach agreements with managers and training responsible.

- Trend to establish individualized training itineraries for the workers.

Professionals of training trends clearly show an increase of the skills they must handle, especially the ones referring to pedagogical and enterprise management competences. These trends are vital for the initial and continuing training processes and they should be taken into account in the study plans of educationalists, as a main professional concern of this working context. Making an analysis of careers related to Education in different European universities (Millan et al., 2005) a trend to consider the specialization in Training in Organizations is observed, as a specialty directed to professionals in the educative context. 


\section{Originality}

This is the first time in our context is performed a study aimed at discovering trends in training in organizations, showing significant matches in the results with other studies of international reference.

A noteworthy trend presented at the ASTD report is the progressive increase of global investment for training, but not as a percentage of the total salary bill, which in fact slightly decreases. This trend is also present in Spain, where the increase is centered at the public investment, not at the private, where it remains the same.

Related to outsourcing, the ASTD report detects an increasing trend in the following services: training content design and training delivery. In Spain, there is not a clear evidence of the enlargement of outsourcing, but a slight tendency in the latest two aspects is observed, having a coincidence with ASTD.

A coincidence is also observed between the ASTD report and our study in regards to the increasing trend in the use of new technologies of information and communication for training, especially by means of e-learning and blended learning. In both studies, the trend to mix different training modalities appears as a good practice for the training approaches.

Considering the evaluation topic, the ASTD report shows a trend where evaluation is carried out by indicators and by means of the investment results for training. In our study, it is also observed a trend to increase the evaluation of the training impact, but with a higher interest in qualitative techniques that are not presented at the European study.

\section{References}

AMERICAN SOCIETY FOR TRAINING AND DEVELOPMENT (2006). Annual Review of Trends in Workplace Learning and Performance. USA.

AMERICAN SOCIETY FOR TRAINING AND DEVELOPMENT (2005). Annual Review of Trends in Workplace Learning and Performance. USA.

AMERICAN SOCIETY FOR TRAINING AND DEVELOPMENT (2004). Annual Review of Trends in Workplace Learning and Performance. USA.

CABRERA, F. (2003). Evaluación de la formación. Madrid: Síntesis. 
CABRERA, F; MILLAN, M.D.; ROMANS, M. (Coords.) (2001). Formació a les organitzacions: Un camp obert als professionals de la pedagogia. Barcelona: Universitat de Barcelona.

CAMBRA DE COMERÇ DE BARCELONA (2003). Observatori de la Formació. Barcelona: Cambra de Comerç de Barcelona.

CEPYME (2003). Autónomos y formación: Necesidades, demandas y resultados. Madrid: CEPYME.

CEREZO, F.; INIESTA, R. (2006). Els formadors de formació contínua a Catalunya: Competències transversals $\mathrm{i}$ detecció de necessitats de formació. Barcelona: Centre d'Estudis Sociolaborals.

DARLING, J.; DARLING, P.; ELLIOT, J. (1999). The changing role of the trainer London: Institute of Personnel and Development.

DELCOURT, J.; PLANAS, J. (1998). Conclusiones y estado del debate. En J. PLANAS (comps.), Agora II: El papel de la empresa en la formación permanente (30-50). CEDEFOP.

EPISE (2000). Planificación de la formación. Barcelona: Ediciones Gestión 2000.

FONT, A.; IMBERNON, F. (2002). Análisis de necesidades de formación. En PINEDA, P. (Coord.), Gestión de la formación en las organizaciones (45-60). Barcelona: Ariel.

FORCEM (2000). Calidad e innovación en la formación continua. Madrid: FORCEM.

FUNDACIÓN TRIPARTITA PARA LA FORMACIÓN Y EL EMPLEO (2006). Estudio del sector de la sanidad privada. http://www.aliad.es/web/index.asp

FRIES, E. (Coord.) (2003). Agora IX. Working time, training time. Thessaloniki: CEDEFOP.

GRÜNEWALD, U. (1996). Formación continua en la empresa: ¿Contribución a la realización de la formación permanente? Revista Europea de Formación Profesional, 8(9): 39-44.

MATEO, J. (2000). La evaluación, su práctica y sus metáforas. Barcelona: Horsori. 
MILLAN, M.D. (1995). Estudi-proposta per afavorir la inserció professional dels pedagogs/gues en la formació professional continuada. Barcelona: Institut Català de Noves Professions.

MILLAN, M.D.; CABRERA, F.; NAVÍO, A.; ROMANS, M.; RUBIO, M.J.; VILADOT, G. (2005). Tendencias de la formación en las organizaciones. Revista de Investigación Educativa, 2(23): 333-361.

NAVIO, A. (2005). Las competencias profesionales del formador. Una visión desde la formación continua. Barcelona: Octaedro.

PINEDA, P. (Coord.) (2003a). Gestión de la formación en las organizaciones. Barcelona: Anagrama.

PINEDA, P. (2003b): Auditoría de la formación. Barcelona: Ediciones Gestión 2000.

PLANAS, J. (Coord.) (1998): Agora II. The role of the company in lifelong learning. Thessaloniki: CEDEFOP.

RUBIO, M.J. (1996). La FP contínua i els agents de formació. Barcelona: Horsori.

RUBIO, M.J. (2003): Enfoques y modelos de evaluación del e-learning, Revista Electrónica de Investigación y Evaluación Educativa, 2(9). http://www.uv.es/RELIEVE/v9n2/RELIEVEv9n2_1.htm

SELKA, R. (1999). Une formation 'orientée vers l'action' pour les formateurs-tuteurs en entreprise. Actualité de la Formation Permanente, 160: 44-49.

SENGE, P. (2006). La quinta disciplina: el arte y la práctica de la organización abierta al aprendizaje. Barcelona: GRANICA.

SENGE, P. (1993). La quinta disciplina. Barcelona: GRANICA.

SELLIN, B. (1998). Co-operation in Research on Trends in the Development of Occupations and Qualifications in the European Union. Thessaloniki: CEDEFOP.

SELLIN, B. (1999). European trends in the development of occupations and qualifications. Luxembourg: Office for Official Publications of the European Communities.

SENNETT, R. (2006). La cultura del nuevo capitalismo. Barcelona: Anagrama. 
STRIETSKA-ILINA, O.; TESSARING, M. (Eds.) (2005). Trends and skill needs in tourism. Luxembourg: Official Publications of the European Communities.

TESSARING, M. (1999). Formación para una sociedad en cambio. Informe acerca de la situación actual de la investigación sobre la formación profesional en Europa. Tesalónica: CEDEFOP.

WITKIN, R.; ALTSCHULD, J. (1995). Planning and conducting needs assessments. Thousand Oaks, CA: Sage.

\section{Appendix}

In the following table shows the results of the study, the responses in percentages for each option for each item or variable.

The options $a, b, c$ and $d$ mean:

a) In our organization the trend is that this aspect will increase

b) In our organization the trend is that this aspect will diminish

c) In our organization the trend is that this aspect will remain

d) In our organization this aspect it is not contemplated

Also it figures $p$, the index of meaningfulness of applying Chi squared to each of the variables.

\begin{tabular}{|c|c|c|c|c|c|}
\hline Training planning future trends & $\mathbf{p}$ & $\mathbf{A}$ & B & $\mathbf{C}$ & D \\
\hline $\begin{array}{l}\text { Linkage of the training planning to the strategic plan of the } \\
\text { enterprise }\end{array}$ & .000 & 78 & 1 & 16 & 5 \\
\hline $\begin{array}{l}\text { Decentralized elaboration of the plan (by work areas, } \\
\text { departments, sectors) }\end{array}$ & .000 & 41 & 7 & 31 & 18 \\
\hline Centralized elaboration of the plan & .036 & 32 & 24 & 30 & 14 \\
\hline Director Managers detect training needs & .000 & 48 & 7 & 41 & 4 \\
\hline Workers detect training needs & .000 & 57 & 3 & 35 & 4 \\
\hline Establishment of training individual itineraries & .000 & 51 & 3 & 26 & 20 \\
\hline Training purposes future trends & $\mathbf{p}$ & $\mathbf{A}$ & B & $\mathbf{C}$ & D \\
\hline $\begin{array}{l}\text { Contribution to the achievement of strategic objectives of the } \\
\text { enterprise }\end{array}$ & .000 & 80 & 2 & 14 & 3 \\
\hline Professional development of workers & .000 & 80 & 2 & 18 & \\
\hline Personal development of workers & .000 & 54 & 4 & 32 & 10 \\
\hline Promotion of workers' motivation and satisfaction & .000 & 70 & 3 & 22 & 5 \\
\hline To overcome problems and difficulties in job & .000 & 71 & 1 & 27 & 1 \\
\hline To facilitate change processes & .000 & 76 & 2 & 17 & 5 \\
\hline To potentiate innovation & .000 & 72 & 2 & 22 & 4 \\
\hline To integrate and share the organization's culture & .000 & 62 & 5 & 31 & 2 \\
\hline Training recipients future trends & $\mathbf{p}$ & $\mathbf{A}$ & B & $\mathbf{C}$ & $\mathbf{D}$ \\
\hline Regular staff & .000 & 50 & 3 & 41 & 5 \\
\hline Technical staff & .000 & 52 & 4 & 41 & 1 \\
\hline
\end{tabular}




\begin{tabular}{|c|c|c|c|c|c|}
\hline Middle Managers & .000 & 66 & 1 & 32 & \\
\hline Director Managers & .000 & 54 & 6 & 36 & 4 \\
\hline Training modalities future trends & $\mathbf{p}$ & $\mathbf{A}$ & B & $\mathbf{C}$ & D \\
\hline Face-to-face training & .000 & 30 & 11 & 56 & 1 \\
\hline Virtual training & .000 & 53 & 4 & 27 & 14 \\
\hline Blended learning (combination conventional-virtual) & .000 & 72 & 1 & 12 & 13 \\
\hline Coaching, mentoring & .000 & 45 & 1 & 23 & 29 \\
\hline Training in job position & .000 & 56 & 2 & 33 & 7 \\
\hline Continuing training resources future trends & $\mathbf{p}$ & $\mathbf{A}$ & B & $\mathbf{C}$ & D \\
\hline Recruitment of external personnel & .000 & 35 & 16 & 36 & 12 \\
\hline Implication of internal personnel & .000 & 55 & 6 & 36 & 3 \\
\hline To fit out training spaces (classrooms, training centers, ...) & .000 & 33 & 9 & 53 & 5 \\
\hline Employment of printed training materials & .000 & 18 & 19 & 57 & 5 \\
\hline Employment of digital training materials & .000 & 69 & 2 & 19 & 9 \\
\hline Employment of simulators & .000 & 33 & 2 & 25 & 39 \\
\hline Financing training with own resources & .000 & 30 & 3 & 59 & 8 \\
\hline Financing training with external grants & .000 & 51 & 4 & 36 & 9 \\
\hline Training evaluation future trends & $\mathbf{p}$ & $\mathbf{A}$ & b & $\mathbf{C}$ & D \\
\hline Linkage of evaluation to the training planning & .000 & 66 & 2 & 21 & 11 \\
\hline I nitial evaluation of competences & .000 & 55 & 3 & 29 & 13 \\
\hline Evaluation of satisfaction & .000 & 47 & 2 & 50 & 1 \\
\hline Evaluation of learning & .000 & 59 & 1 & 36 & 3 \\
\hline Evaluation of transference to job position & .000 & 66 & & 28 & 6 \\
\hline Evaluation of the impact on the organization (results) & .000 & 62 & & 28 & 10 \\
\hline $\begin{array}{l}\text { Evaluation of training profitability (ROI, operating statements, } \\
\text { ratios, ....) }\end{array}$ & .000 & 51 & 2 & 28 & 19 \\
\hline $\begin{array}{l}\text { Employment of quantitative techniques (questionnaires, tests, } \\
\text {...) }\end{array}$ & .000 & 37 & 2 & 48 & 13 \\
\hline $\begin{array}{l}\text { Employment of qualitative techniques (observation, interviews, } \\
\text { meetings, ...) }\end{array}$ & .000 & 50 & 3 & 35 & 12 \\
\hline Employment of a training quality management system & .000 & 47 & 1 & 27 & 22 \\
\hline Which quality management system is employed? & \multicolumn{5}{|c|}{ ISO:25; FQM: 7; others: 6} \\
\hline Training professionals future trends & $\mathbf{p}$ & $\mathbf{A}$ & B & $\mathbf{C}$ & $\mathbf{D}$ \\
\hline Incorporation of personnel dedicated to training & .000 & 19 & 6 & 58 & 16 \\
\hline Professionalization of the personnel dedicated to training & .000 & 41 & 1 & 43 & 14 \\
\hline Presence of a training responsible & .000 & 33 & & 57 & 9 \\
\hline $\begin{array}{l}\text { Training responsibles must have knowledge on enterprise } \\
\text { management }\end{array}$ & .000 & 40 & 1 & 33 & 24 \\
\hline $\begin{array}{l}\text { Training responsibles must have knowledge on the activity } \\
\text { sector of the enterprise }\end{array}$ & .000 & 60 & 2 & 30 & 7 \\
\hline Training responsibles must have pedagogical knowledge & .000 & 55 & 1 & 34 & 8 \\
\hline Training responsibles must possess interpersonal abilities & .000 & 65 & 1 & 29 & 4 \\
\hline Training outsourcing future trends & $\mathbf{p}$ & A & B & C & D \\
\hline Needs detection & .000 & 31 & 5 & 33 & 27 \\
\hline Training plan design & .000 & 25 & 6 & 41 & 24 \\
\hline Training actions design & .000 & 36 & 3 & 44 & 13 \\
\hline Training delivery & .000 & 40 & 3 & 50 & 3 \\
\hline Management of public grants & .000 & 41 & 4 & 36 & 15 \\
\hline Training evaluation & .000 & 33 & 4 & 41 & 18 \\
\hline Training materials elaboration & .000 & 39 & 2 & 43 & 12 \\
\hline
\end{tabular}

Intangible Capital, 2011 (www.intangiblecapital.org)

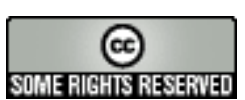

Article's contents are provided on a Attribution-Non Commercial 3.0 Creative commons license. Readers are allowed to copy, distribute and communicate article's contents, provided the author's and Intangible Capital journal's names are included. It must not be used for commercial purposes. To see the complete licence contents, please visit http://creativecommons.org/licenses/by-nc/3.0/es/ 